\title{
A young lady with dyspnoea: Quest for the cause
}

\author{
Mahismita Patro, Dipti Gothi, Sameer Vaidya \\ Department of Pulmonary Medicine, ESI-PGIMSR, New Delhi, India
}

\begin{abstract}
Pulmonary hypertension (PH) is a common cause of dyspnoea. The management and prognosis of $\mathrm{PH}$ varies with the underlying aetiology. Hence the detection of the cause of $\mathrm{PH}$ is important. Obliterative bronchiolitis (OB) is a common but under-recognised cause of $\mathrm{PH}$. OB is usually secondary to childhood infections known as post-infectious OB. It can also be secondary to other diseases, but cryptogenic $\mathrm{OB}$ is an extremely rare entity. Here we share a unique case of $\mathrm{PH}$ due to cryptogenic $\mathrm{OB}$ and its successful outcome with optimal management.
\end{abstract}

\section{Case Report}

A 31-year-old lady presented with progressive dyspnoea on exertion. The grade of dyspnoea had progressed from modified

Correspondence: Dr Dipti Gothi, Department of Pulmonary Medicine, ESI-PGIMSR, New Delhi.

E-mail: diptigothi@gmail.com

Contributions: All the authors made a substantive intellectual contribution. All the authors have read and approved the final version of the manuscript and agreed to be accountable for all aspects of the

Key words: Pulmonary hypertension; obliterative bronchiolitis; mosaic attenuation.

Conflict of interest: The authors declare that they have no competing interests, and all authors confirm accuracy.

Informed consent: Written and informed consent was obtained from the patient.

Acknowledgements: We sincerely acknowledge the Departments of Pulmonary Medicine, Cardiology and Radiology of our Institute for their cooperation in successful management of this case.

Received for publication: 21 February 2021.

Accepted for publication: 26 May 2021.

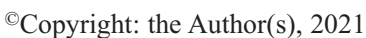

Licensee PAGEPress, Italy

Monaldi Archives for Chest Disease 2021; $91: 1812$

doi: 10.4081/monaldi.2021.1812

This article is distributed under the terms of the Creative Commons Attribution Noncommercial License (by-nc 4.0) which permits any noncommercial use, distribution, and reproduction in any medium, provided the original author(s) and source are credited.
Medical Research Council (mMRC) grade 1 to 3 in the last 6 months. She had no other symptoms. There was no history of snoring or excessive daytime sleepiness. She also denied of the symptoms of joint pain, skin tightening, dysphagia, muscle weakness or skin rash. She had primary hypothyroidism for 3 years and was on thyroxine $100 \mu \mathrm{g}$ per day. She did not have any other comorbidity. There was no prior history of tuberculosis, childhood pneumonia, recurrent respiratory tract infections or nasobronchial allergies. She never used tobacco, alcohol or illicit drugs. There was no exposure to biomass fuels or any occupational or environmental dusts. She was multiparous. The first child was born 3 years earlier by caesarean section at term. The second pregnancy got terminated after 3 months due to spontaneous abortion 6 months earlier.

The patient was hemodynamically stable with a pulse rate of $106 / \mathrm{min}$, respiratory rate of $18 / \mathrm{min}$ and blood pressure of $140 / 80$ $\mathrm{mm} \mathrm{Hg}$. She had a body mass index of $31.2 \mathrm{~kg} / \mathrm{m}^{2}$. The six minute walk test revealed a distance of $162 \mathrm{~m}$ and a drop in oxygen saturation from $98 \%$ to $86 \%$. The auscultation of the chest revealed bilateral normal vesicular breath sounds without any added sounds. The other systems examination was normal.

The chest radiograph showed cardiomegaly with enlarged right pulmonary artery (Figure 1). The electrocardiograph showed presence of ' $p$ '-pulmonale, right axis deviation and right ventricular hypertrophy. The echocardiography showed enlargement of the right atrium, right ventricle and severe tricuspid regurgitation with a velocity gradient of $4.39 \mathrm{~m} / \mathrm{s}$. The estimated right ventricular systolic pressure was $87 \mathrm{mmHg}$. The left ventricular ejection fraction was $55 \%$.

The routine blood investigations revealed haemoglobin of 14 $\mathrm{g} / \mathrm{dl}$, total leucocyte count of $7400 / \mu \mathrm{l}$ and random blood sugar of $109 \mathrm{mg} / \mathrm{dl}$. Her serum urea was $22 \mathrm{mg} / \mathrm{dl}$ and creatinine was 0.7 $\mathrm{mg} / \mathrm{dl}$. The thyroid stimulating hormone level was $0.5 \mu \mathrm{IU} / \mathrm{ml}$ (normal range, 0.35 to $5.50 \mu \mathrm{IU} / \mathrm{ml}$ ). The enzyme linked immunosorbent assay for human immunodeficiency virus was negative. The rheumatoid arthritis factor, antinuclear antibody assay and anti-dsDNA antibody tests were negative. The ultrasound of the abdomen was normal. The spirometry showed a forced expiratory volume in $1^{\text {st }}$ second $\left(\mathrm{FEV}_{1}\right)$ of 0.861 (31\% predicted), forced vital capacity (FVC) of 1.471 (46\% predicted) and $\mathrm{FEV}_{1} / \mathrm{FVC}$ ratio of 0.58 . The peak expiratory flow rate was 2.55 $1 / \mathrm{s}$ (39\% of predicted) and maximum mid expiratory flow rate was $0.571 / \mathrm{s}$ (14\% predicted). She was not able to perform the diffusing capacity of lungs for carbon monoxide (DLCO). The computed tomography (CT) scan images of the chest are shown in Figure 2. The initial evaluation suggested a diagnosis of pulmonary hypertension $(\mathrm{PH})$ based on the clinical history, chest radiograph and echocardiography. She was further investigated to find out the cause of PH. The serological investigations did not reveal any abnormality. The spirometry showed a mixed obstructive and restrictive pattern. The contrast enhanced CT scan of the chest showed the presence of dilated main pulmonary artery. The high resolution CT (HRCT) scan showed areas of mosaic attenuation 
(Figure 2). The pulmonary vessels were reduced in size in the areas with low attenuation. There was accentuation of mosaic attenuation on the expiratory scan. These findings were suggestive of small airway obstruction. There was no other identifiable cause of obstructive airway disease. So, our patient had a final diagnosis of Group 3 pulmonary hypertension ( $\mathrm{PH}$ ) due to cryptogenic obliterative bronchiolitis (OB).

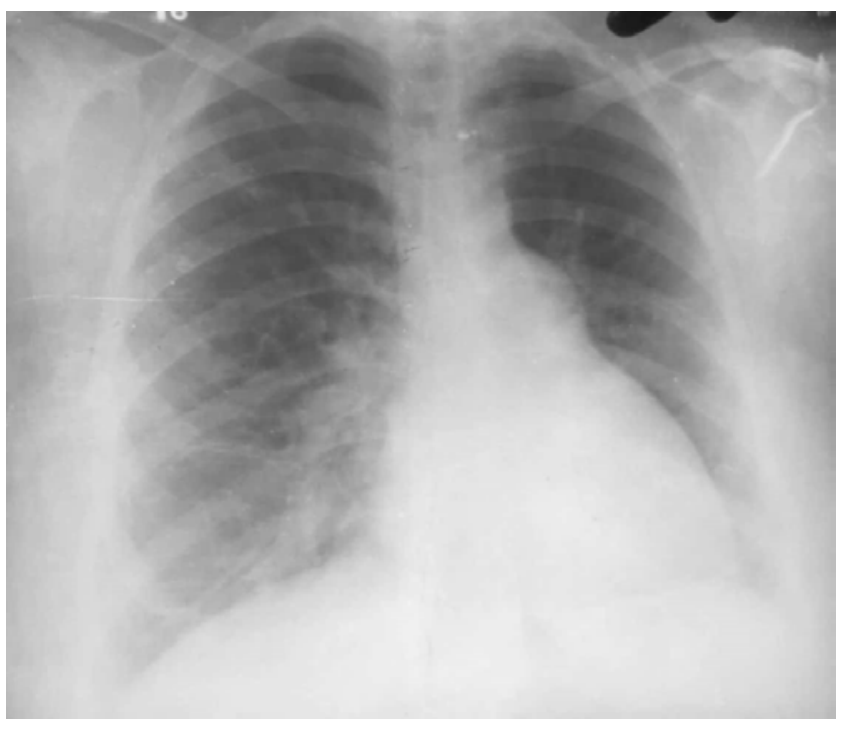

Figure 1. Chest radiograph in posteroanterior projection showing cardiomegaly and enlarged right pulmonary artery. The lung fields appear normal.
She was started on inhaled bronchodilators. She had a significant symptomatic relief with improvement in dyspnoea. The 6 minute walk distance improved from $162 \mathrm{~m}$ at baseline to $332 \mathrm{~m}$ after 1 month, and $448 \mathrm{~m}$ after 4 months. The follow-up echocardiography after 1 month also showed reduction in the right ventricular systolic pressure to $41 \mathrm{mmHg}$. The spirometry after 4 months showed improvement in $\mathrm{FEV}_{1}$ and FVC by $500 \mathrm{ml}$ and $510 \mathrm{ml}$ respectively. The diffusion studies could be performed after the treatment. It showed a DLCO of $17.27 \mathrm{ml} / \mathrm{mmHg} / \mathrm{min}(69 \%$ predicted). The RV/TLC was $48.09 \%$ suggestive of residual air-trapping.

\section{Discussion}

$\mathrm{PH}$ is a life-threatening disease characterized by an increase in the mean pulmonary artery pressure to $\geq 25 \mathrm{mmHg}$ at rest [1]. The recent $6^{\text {th }}$ world symposium on $\mathrm{PH}$ suggested lowering this threshold to $>20 \mathrm{mmHg}$ [2]. $\mathrm{PH}$ has been classified into five groups based on the aetiology, clinical presentation and management strategy. Before classifying a patient as idiopathic pulmonary arterial hypertension, all the other known causes need to be ruled out by detailed clinical evaluation and appropriate investigations. The workup includes chest radiograph, electrocardiogram, echocardiography, immunological tests, pulmonary function tests, thoracic CT scan, ventilation-perfusion lung scan, cardiac magnetic resonance imaging, assessment for the connective tissue disease, abdominal ultrasound, pulmonary angiography, right heart catheterisation (RHC), etc. The required investigations are to be decided on a case to case basis based on the clinical assessment.

On echocardiography, the probability of PH can be assessed based on the peak tricuspid regurgitation velocity. The maximum tricuspid regurgitation velocity is used as a surrogate of right ven-

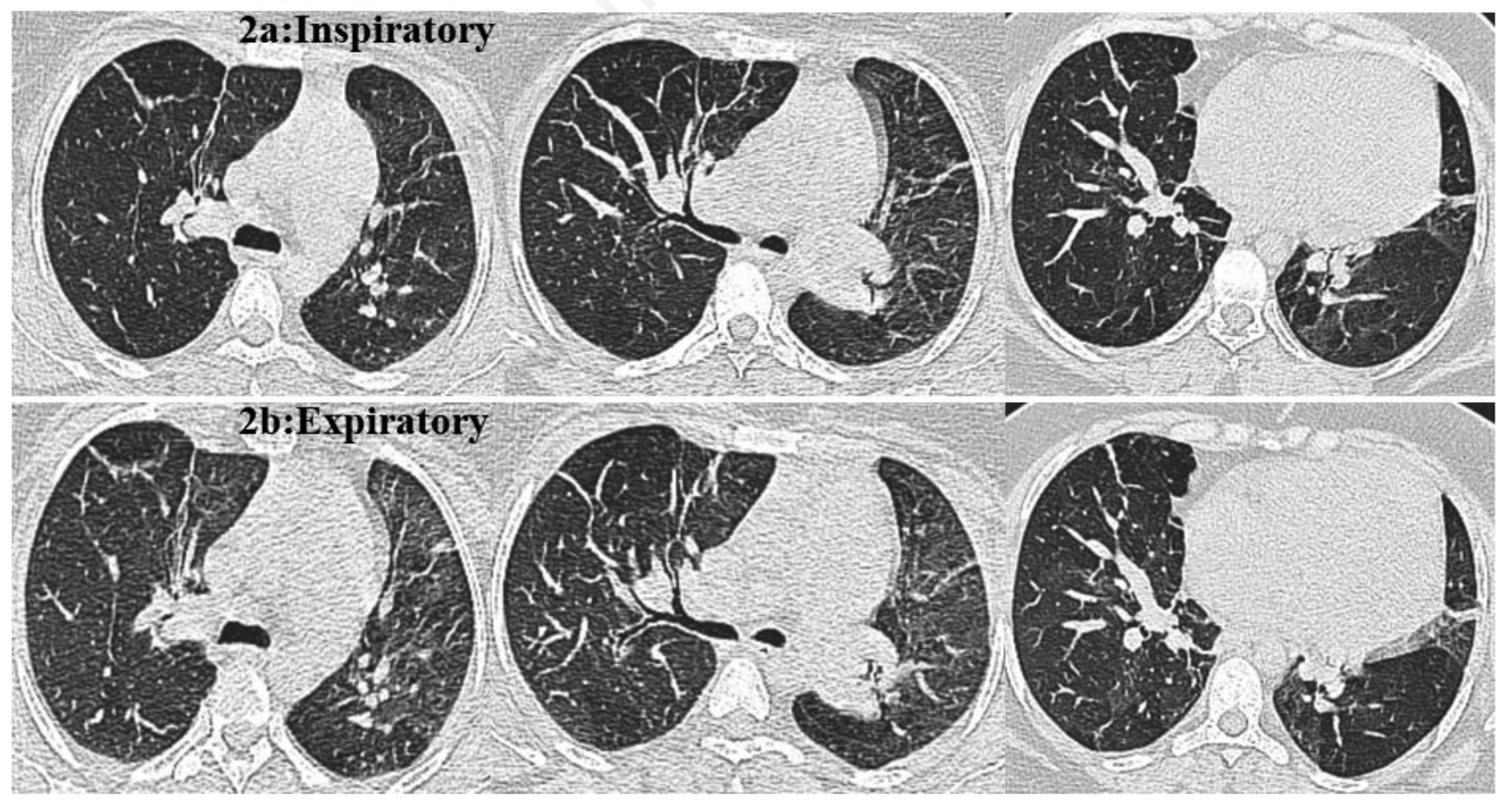

Figure 2. HRCT scan of the chest in lung window. a) Inspiratory images. b) Expiratory images. 
tricular systolic pressure. The probability of $\mathrm{PH}$ is low if the velocity is $\leq 2.8 \mathrm{~m} / \mathrm{s}$, it is intermediate if the velocity is 2.9 to $3.4 \mathrm{~m} / \mathrm{s}$ and it is high if the velocity is $>3.4 \mathrm{~m} / \mathrm{s}$. The RHC is recommended for confirmation of the diagnosis of pulmonary arterial hypertension and chronic thromboembolic $\mathrm{PH}$ as well as for the hemodynamic characterisation of $\mathrm{PH}$.. Being an invasive procedure, the benefits of performing the RHC should be weighed against the risks involved. The RHC is not indicated routinely if the PH is secondary to left heart disease or lung disease and there are no therapeutic implications. In these patients, RHC is reserved for those with disproportionate $\mathrm{PH}$ or if organ transplantation is considered or to support the treatment decisions [1]. Since our patient had PH secondary to lung disease she was evaluated by a multi-disciplinary team (MDT) consisting of pulmonologists, cardiologists and radiologists for the possible need of RHC. The risk benefit ratio was evaluated and it weighed against the invasive procedure. The patient was also counselled regarding the same. Both the MDT and the patient opted for initiating the treatment for lung disease, with RHC if no improvement. As she subsequently improved with treatment, RHC was avoided.

The small airway diseases (SAD) are also known to cause group $3 \mathrm{PH}$. The patients with SAD clinically present with progressive dyspnoea and cough. Their physical examination may be normal or may reveal rhonchi or inspiratory crackles. The clinical findings may sometimes be subtle and confusing. The spirometry in SAD may show obstructive or restrictive pattern. There may be false normalisation of the $\mathrm{FEV}_{1} / \mathrm{FVC}$ ratio due to a similar reduction in the $\mathrm{FEV}_{1}$ and FVC. The changes can be detected by the pulmonary function tests only after involvement of $75 \%$ of the small airways. The DLCO may be normal or reduced. An increase in the ratio of residual volume to total lung capacity (RV/TLC) is a sign of air trapping in the SAD. The HRCT scan shows mosaic attenuation which worsens on the expiratory scan $[3,4]$. In our patient, based on the clinico-radiological assessment and spirometry findings the diagnosis was of PH secondary to SAD. Hence initiation of treatment was favoured over performing invasive RHC.

The heterogeneous attenuation or mosaic attenuation of the lungs refers to the radiographic pattern of high and low attenuation areas on the HRCT scan. This can be seen in SAD, vascular disease and infiltrative lung disease. The approach to mosaic attenuation is given in Figure 3. The first step is to find out which portion of the lung parenchyma is abnormal. The size and number of peripheral pulmonary vessels helps in determining the abnormal parenchyma. The presence of uniform vessel distribution in high and low attenuation areas with ground glass opacity suggests infiltrative lung disease. The presence of decreased vasculature in low attenuation areas suggests either SAD or vascular disease. An expiratory HRCT scan is required to differentiate between the SAD and the vascular disease. If the mosaic pattern worsens on the expira- tory scan it confirms the diagnosis of SAD. The CT findings in SAD are related to the physiological mechanism of hypoxic pulmonary vasoconstriction. In the obstructed areas there occurs resultant hypoperfusion with shunting of blood away to other areas. This creates mosaicism with hypoattenuation in the airtrapped areas and hyperattenuation in normally ventilated areas. On expiration, the difference in attenuation becomes more pronounced because the loss of air from the normal areas increases attenuation whereas the attenuation of the air-trapped areas remains unchanged. The HRCT in our patient also showed accentuation of mosaic pattern on the expiratory scan classical of SAD (Figure 2). The HRCT scan may also show additional findings of the particular disease. The presence of centrilobular nodules, treein-bud nodules, bronchial wall thickening and bronchiectasis suggest SAD [5-7].

The causes of SAD are many; they can be broadly classified under three groups as mentioned in Table 1. OB is one of the commonest causes of SAD. It constitutes the group of small airway respiratory diseases characterised by concentric fibrosis in the submucosal layer of the bronchioles. OB is also named as constrictive bronchiolitis or bronchiolitis obliterans [8]. OB is diagnosed when all other known causes of chronic airflow obstruction such as asthma, chronic obstructive airway disease, occupational exposures, and bronchiectasis have been ruled out based on the clinico-radiological assessment [5]. The accentuation of the areas of airtrapping on the expiratory HRCT scan of the lung in the correct clinical context is diagnostic of $\mathrm{OB}$ [4]. The histopathological findings in $\mathrm{OB}$ are confusing due to overlap, and are rarely diagnostic [9]. Thus the lung biopsy is not essential for the diagnosis of OB routinely. However biopsy is recommended prior to lung transplantation for diagnostic certainty and ruling out other possible causes. As our patient improved significantly with bronchodilators, biopsy was not required.

$\mathrm{OB}$ in the developing countries is frequently secondary to childhood viral infections and is known as post-infectious OB [10]. The commonest cause of $\mathrm{OB}$ in the developed countries is posttransplant, known as bronchiolitis obliterans syndrome. The other causes of $\mathrm{OB}$ include connective tissue diseases, inhalational injury due to toxic gases e.g. $\mathrm{NO}_{2}$, ammonia, and phosgene, drug induced e.g. penicillamine, inflammatory bowel disease \& popcorn manufacturing [11]. When no obvious cause can be identified it is termed as cryptogenic or idiopathic OB. The term cryptogenic OB was coined by Turton et al. to characterize the cases of otherwise unexplained progressive airflow obstruction [12]. Our patient was labelled as cryptogenic OB after ruling out all other possible causes based on the detailed clinical history. The literature on cases of cryptogenic OB is very scarce. To the best of our knowledge none has been reported to initially present with severe pulmonary hypertension $[13,14]$. The management of OB involves bron-

Table 1. Causes of the small airway diseases.

\begin{tabular}{|c|c|c|}
\hline Primary bronchiolar disorders & $\begin{array}{l}\text { ILDs with a prominent bronchiolar } \\
\text { involvement }\end{array}$ & $\begin{array}{l}\text { Bronchiolar involvement in large airway } \\
\text { diseases }\end{array}$ \\
\hline $\begin{array}{l}\text { Constrictive/obliterative bronchiolitis } \\
\text { Diffuse panbronchiolitis } \\
\text { Respiratory bronchiolitis } \\
\text { Infectious bronchiolitis } \\
\text { Follicular bronchiolitis } \\
\text { Mineral dust airway disease } \\
\text { Aspiration bronchiolitis }\end{array}$ & $\begin{array}{l}\text { Hypersensitivity pneumonitis } \\
\text { Respiratory bronchiolitis associated ILD } \\
\text { Desquamative interstitial pneumonia } \\
\text { Cryptogenic organizing pneumonia } \\
\text { Other interstitial diseases }\end{array}$ & $\begin{array}{l}\text { Chronic bronchitis } \\
\text { Asthma } \\
\text { Bronchiectasis } \\
\text { Cystic fibrosis }\end{array}$ \\
\hline
\end{tabular}

ILD, interstitial lung disease. 


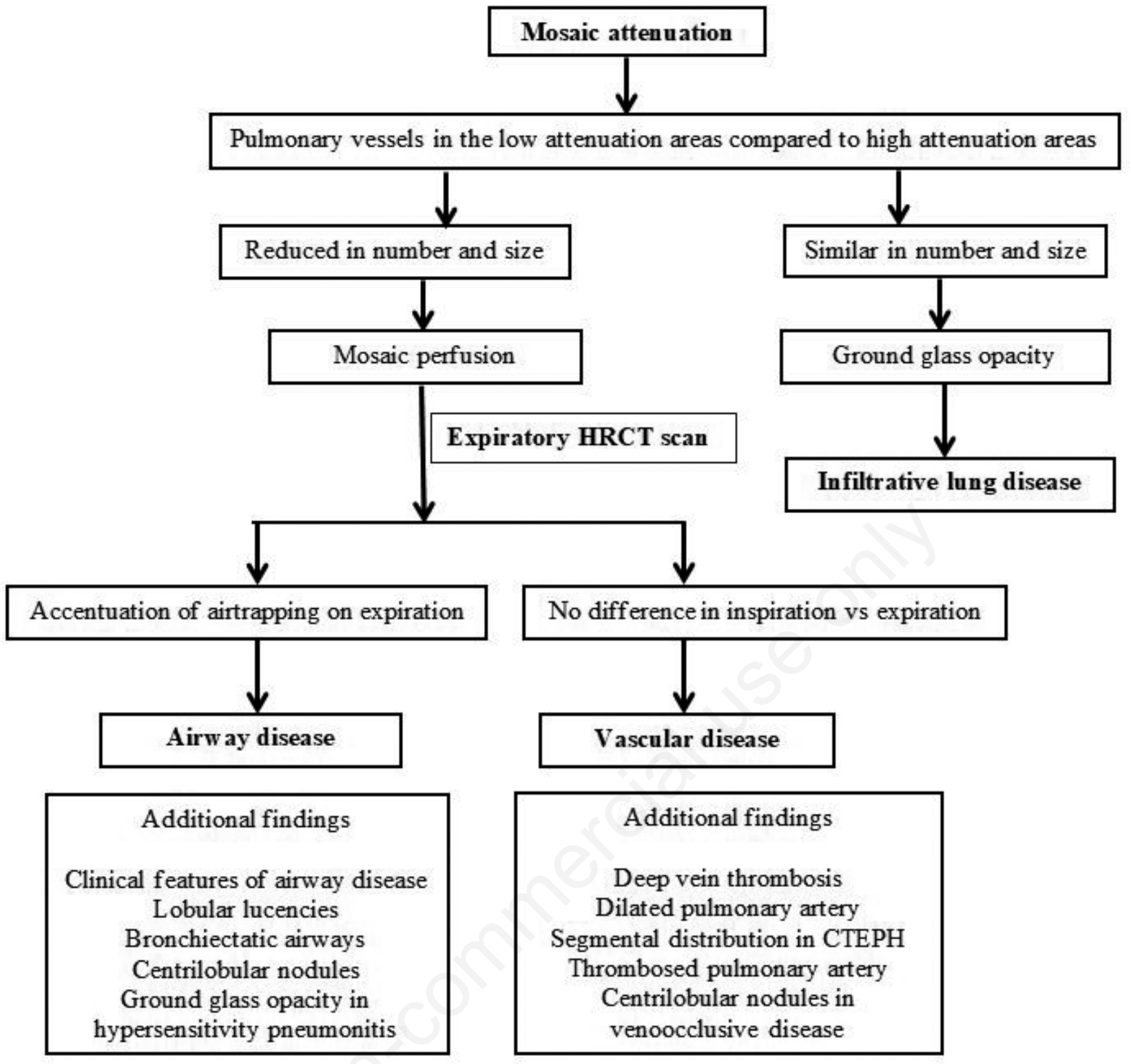

Figure 3. Flowchart showing the approach to the assessment of mosaic attenuation.

chodilators and treatment of underlying disorder. The recent evidences have shown that the microfine inhalers are better than the standard inhalers in the management of OB. The role of oral corticosteroids is doubtful. The trials have shown that corticosteroids are not beneficial in the management of $\mathrm{OB}$. The prognosis of $\mathrm{OB}$ depends on the etiology $[8,15]$.

\section{Conclusions}

The identification of the exact cause of $\mathrm{PH}$ is important, as the management varies with the cause. The HRCT chest pattern of mosaic attenuation can be seen in infiltrative lung disorders, small airway diseases and vascular diseases. The accentuation of mosaic pattern on the expiratory HRCT scan is diagnostic of SAD. Cryptogenic OB can be diagnosed when other known causes of SAD are ruled out.

\section{References}

1. Galiè N, Humbert M, Vachiery JL, et al. ESC Scientific Document Group, 2015 ESC/ERS Guidelines for the diagnosis and treatment of pulmonary hypertension: The Joint Task Force for the Diagnosis and Treatment of Pulmonary Hypertension of the European Society of Cardiology (ESC) and the European Respiratory Society (ERS). Eur Heart J 2016;37:67-119.

2. Simonneau G, Montani D, Celermajer DS, et al. Haemodynamic definitions and updated clinical classification of pulmonary hypertension. Eur Respir J 2019;53:1801913.

3. Burgel PR, Bergeron A, de Blic J, et al. Small airways diseases, excluding asthma and COPD: an overview. Eur Respir Rev 2013;22:131-47.

4. Hansell DM. Small airways disease: Detection and insights with computed tomography. Eur Respir J 2001;17:1294-313. 
5. Raju S, Ghosh S, Mehta AC. Chest CT signs in pulmonary disease. A pictorial review. Chest 2017;151:1356-74.

6. Kligerman SJ, Henry T, Lin CT, et al. Mosaic attenuation: Etiology, methods of differentiation, and pitfalls. Radiographics 2015 35:1360-80.

7. Lewis G, Hoey ETD, Reynolds JH, et al. Multi-detector CT assessment in pulmonary hypertension: techniques, systematic approach to interpretation and key findings. Quant Imaging Med Surg 2015;5:423-32.

8. Epler GR. Diagnosis and treatment of constrictive bronchiolitis. F1000 Med Rep 2010;2:32.

9. Markopoulou KD, Cool CD, Elliot TL, et al. Obliterative bronchiolitis: varying presentations and clinicopathological correlation. Eur Respir J 2002;19:20-30.

10. Joshi JM, Gothi D. Post infectious obliterative bronchiolitis. Lung India 2006;23:75-7.
11. Epler GR. Constrictive bronchiolitis obliterans: the fibrotic airway disorder. Expert Rev Resp Med 2007;1:139-47.

12. Turton CW, Williams G, Green M. Cryptogenic obliterative bronchiolitis in adults. Thorax 1981;36:805-10.

13. Kraft M, Mortenson RL, Colby TV, et al. Cryptogenic constrictive bronchiolitis. A clinicopathologic study. Am Rev Respir Dis 1993;148:1093-101.

14. Callahan SJ, Vranic A, Flors L, et al. Sporadic obliterative bronchiolitis: Case series and systematic review of the literature. Mayo Clin Proc Innov Qual Outcomes 2019 $1 ; 3: 86-93$.

15. Jerkic SP, Brinkmann F, Calder A, et al. Postinfectious bronchiolitis obliterans in children: Diagnostic workup and therapeutic options: A workshop report. Can Respir J 2020; 2020:5852827. 